\title{
Article \\ Caregiver Willingness to Vaccinate Their Children against COVID-19 after Adult Vaccine Approval
}

\author{
Ran D. Goldman ${ }^{1, *}$, Danna Krupik ${ }^{2}$, Samina Ali ${ }^{3}$, Ahmed Mater ${ }^{4}{ }^{\mathbb{D}}$, Jeanine E. Hall ${ }^{5}$, Jeffrey N. Bone ${ }^{6} \mathbb{D}$, \\ Graham C. Thompson ${ }^{7}$ (D), Kenneth Yen ${ }^{8}$, Mark A. Griffiths ${ }^{9}$, Adi Klein ${ }^{10}$, Eileen J. Klein ${ }^{11}$, Julie C. Brown ${ }^{11}$, \\ Rakesh D. Mistry ${ }^{12}$, Renana Gelernter ${ }^{13}$ and on behalf of the International COVID-19 Parental Attitude Study \\ (COVIPAS) Group ${ }^{+}$
}

\section{check for} updates

Citation: Goldman, R.D.; Krupik, D.; Ali, S.; Mater, A.; Hall, J.E.; Bone, J.N.; Thompson, G.C.; Yen, K.; Griffiths, M.A.; Klein, A.; et al. Caregiver Willingness to Vaccinate Their Children against COVID-19 after Adult Vaccine Approval. Int. J. Environ. Res. Public Health 2021, 18, 10224. https://doi.org/10.3390/ ijerph181910224

Academic Editor: Zahid Ahmad Butt

Received: 31 August 2021

Accepted: 23 September 2021

Published: 28 September 2021

Publisher's Note: MDPI stays neutra with regard to jurisdictional claims in published maps and institutional affiliations.

Copyright: (c) 2021 by the authors Licensee MDPI, Basel, Switzerland. This article is an open access article distributed under the terms and conditions of the Creative Commons Attribution (CC BY) license (https:// creativecommons.org/licenses/by/ $4.0 /)$
1 The Pediatric Research in Emergency Therapeutics (PRETx) Program, Department of Pediatrics, Division of Emergency Medicine, BC Children's Hospital Research Institute, University of British Columbia, Vancouver, BC V6H 3N1, Canada

2 Ziv Medical Center, Pediatric Emergency Unit, Azrieli Faculty of Medicine, Bar-Ilan University, Safed 5290002, Israel; dannak@ziv.gov.il

3 Departments of Pediatrics, Faculty of Medicine \& Dentistry, Women and Children's Health Research Institute, University of Alberta, Edmonton, AB T6G 2R3, Canada; sali@ualberta.ca

4 Pediatric Emergency Medicine, Jim Pattison Children's Hospital, University of Saskatchewan, Saskatoon, SK S7N 5B5, Canada; mater999@me.com

5 Division of Emergency and Transport Medicine, Children's Hospital Los Angeles, USC Keck School of Medicine, Los Angeles, CA 90033, USA; jehall@chla.usc.edu

6 Biostatistical Lead, Research Informatics, BC Children's Hospital Research Institute, Vancouver, BC V5Z 4H4, Canada; jeffrey.bone@cw.bc.ca

7 Pediatrics and Emergency Medicine, Alberta Children's Hospital, University of Calgary, Calgary, AB T2N 1N4, Canada; graham.thompson@albertahealthservices.ca

8 Division of Pediatric Emergency Medicine, Department of Pediatrics, University of Texas Southwestern Children's Health, Dallas, TX 75235, USA; ken.yen@utsouthwestern.edu

9 Division of Pediatric Emergency Medicine, Children's Healthcare of Atlanta, Emory School of Medicine, Atlanta, GA 30322, USA; mark.anthony.griffiths@emory.edu

10 Hillel Yaffe Medical Center, Department of Pediatrics, Hadera and Technion Faculty of Medicine, Haifa 38100, Israel; adi@hy.health.gov.il

11 Seattle Children's Hospital, University of Washington School of Medicine, Seattle, WA 98195, USA; eileen.klein@seattlechildrens.org (E.J.K.); Julie.brown@seattlechildrens.org (J.C.B.)

12 Department of Pediatrics, Section of Emergency Medicine, University of Colorado Denver, Aurora, CO 80204,USA; rakesh.mistry@childrenscolorado.org

13 Shamir Medical Center, Pediatric Emergency Medicine Unit, Sackler Faculty of Medicine, Tel Aviv University, Tel Aviv 6997801, Israel; grenana@gmail.com

* Correspondence: rgoldman@cw.bc.ca; Tel.: +1-604-875-2345 (ext. 7333)

+ For the International COVID-19 Parental Attitude Study (COVIPAS) Group. A complete list of the COVIPAS group appears in the Acknowledgements.

Abstract: Vaccines against COVID-19 are likely to be approved for children under 12 years in the near future. Understanding vaccine hesitancy in parents is essential for reaching herd immunity. A cross-sectional survey of caregivers in 12 emergency departments (ED) was undertaken in the U.S., Canada, and Israel. We compared reported willingness to vaccinate children against COVID-19 with an initial survey and post-adult COVID-19 vaccine approval. Multivariable logistic regression models were performed for all children and for those $<12$ years. A total of 1728 and 1041 surveys were completed in phases 1 and 2, respectively. Fewer caregivers planned to vaccinate against COVID-19 in phase $2(64.5 \%$ and $59.7 \%$, respectively; $p=0.002)$. The most significant positive predictor of willingness to vaccinate against COVID-19 was if the child was vaccinated per recommended local schedules. Fewer caregivers plan to vaccinate their children against COVID-19, despite vaccine approval for adults, compared to what was reported at the peak of the pandemic. Older caregivers who fully vaccinated their children were more likely to adopt vaccinating children. This study can inform target strategy design to implement adherence to a vaccination campaign. 
Keywords: vaccine hesitancy; parental attitudes; COVID-19

\section{Introduction}

Vaccine hesitancy, defined as a delay in the acceptance or refusal of vaccines despite the availability of vaccine services [1,2], has increased over recent years [3-6] and was recognized as one of the top ten threats to global health in 2019 [7]. A 2019 national survey from the United States (U.S.) found that approximately one out of four parents reported serious concerns towards vaccinating their children [8] and parental vaccine hesitancy in regard to their children may hamper efforts to curtail the COVID-19 pandemic [9]. In March 2020, the Center for Disease Control and Prevention's (CDC) National Immunization Survey data revealed that more than $30 \%$ of U.S. children between the ages of 19 and 35 months were not following the recommended early childhood immunization schedule [10]. The complexity of vaccine hesitancy is derived from over 70 independent variables [11], predominantly psychological barriers (e.g., perceived risk, usefulness, and social benefit), contextual barriers (e.g., access to health care services), and lifestyle (e.g., smoking, drinking, and physical activity) [12].

As vaccines for children under 12 years are in late stages of clinical trials, there is importance in understanding parental attitudes and preferences in regard to accepting future COVID-19 vaccines for their children. This information can help public heath officers design specific campaigns to enhance vaccine acceptance and improve herd immunity. Previous studies have focused on understanding and addressing individual and community vaccine hesitancy $[4-6,13]$. Concerns about vaccine hesitancy have been further heightened during the COVID-19 pandemic, at a time when reaching herd immunity is essential to public health and mitigation of widespread infection. At the end of 2020, during the height of the COVID-19 pandemic, the U.S. Food and Drug Administration (FDA) provided emergency approval for COVID-19 vaccines, and Americans grew confident in their safety and effectiveness, with $60 \%$ stating they definitely or probably would get vaccinated [14]. Yet, when it came to vaccinating children, a poll of over 1200 parents in May 2021 revealed that just half (53\%) planned to vaccinate eventually, and only a quarter of parents $(26 \%)$ reported they would vaccinate 'right away' [15]. Our study team recently reported that among 1541 parents visiting 16 emergency departments (EDs) in six countries during the peak of the COVID-19 pandemic, 65\% said they would vaccinate their children [16]. Another study conducted in England found that $48.2 \%$ parents of young infants indicated they would vaccinate their children [17]. However, lower COVID-19 vaccine acceptance rates in children were reported in other recent studies (33.9-36.3\%) [18,19].

In May 2021, a COVID-19 vaccine was first approved for ages 12-15 years by Health Canada [20] and subsequently by the FDA in the U.S. Our study focused on the experience of parents who may have received the vaccine themselves or learned about the vaccine experience of others either from conversations or the media, prior to approval for use in children or adolescents. The objective of this follow-up study was to determine how COVID-19 vaccine approval for adults was associated with caregiver likelihood to vaccinate their children.

\section{Materials and Methods}

\subsection{Sample and Procedures}

This cross-sectional study was part of the COVID-19 Parental Attitude Study (COVIPAS) of caregivers presenting for emergency care for their children during the era of COVID-19. Subjects included all caregivers who arrived at one of 12 pediatric emergency departments (EDs) in the U.S. (Denver, Los Angeles, Dallas, Seattle, Atlanta), Canada (Vancouver, Saskatoon, Edmonton, Calgary) and Israel (Zerifin, Hedera, Safed). Caregivers were recruited using posters placed in waiting areas and patient rooms, as well as direct approach by team members. For infectious control purposes, caregivers used their own smartphones 
to scan a QR code to access the survey by logging into a secured online platform based on the REDCap metadata-driven platform (Vanderbilt University). Once a caregiver selected their study site, consent for participation was implied. This study was approved by each site's local Institutional Review Board (IRB).

The initial phase 1 was conducted during the peak of the pandemic (March-May 2020) and a revised survey, after a COVID-19 vaccine became available for adults through emergency authorization in all three countries (phase 2), was conducted from December 2020 to March 2021. The revised survey was available in English, French, and Hebrew. Only one caregiver completed the survey per visit, and due to restrictions to visitation in most sites, only one caregiver was in the room with each child.

\subsection{Measures}

The study-specific questionnaire was developed to include questions regarding demographic characteristics, information regarding the ED visit, and caregiver attitudes about vaccinating against COVID-19. The survey objective was to compare caregivers perspectives and actions before and after a vaccine was available for adults. We have previously described the development and validation of the original survey [16]. The main outcome measure in the study was the rate of parents who plan to vaccinate their children 12 years and younger once a vaccine becomes available. We also asked parents about their level of concern about them or their child having COVID-19, as well as losing work during the pandemic or their children losing school days.

\subsection{Data Analysis}

Descriptive statistics and frequencies were used to describe all variables. Phase 1 and phase 2 were compared using the Mann-Whitney tests for comparing non-normal continuous variables, independent $t$-tests for comparing normally distributed continuous variables, and Chi-square or Fisher's exact tests for comparing categorical variables, with a significance level of 0.05 . We then fit multivariable logistic regression models stratified by phase to compare relevant a priori identified predictors of caregiver intent to vaccinate against COVID-19. Results from these models were summarized with adjusted odds ratios and $95 \%$ confidence intervals. Significance for the multivariable models was set at 0.05 . Similar analyses were conducted in a subgroup of parents whose child being seen in the ED was less than 12 years of age. All analyses were conducted with $R$ version 4.0.3 (R Core Team, Vienna, Austria).

\section{Results}

A total of 2769 surveys were completed with 1728 in phase 1 (pre adult vaccine approval) and 1041 in phase 2 (post vaccine approval 2020-2021). There were 1499 (54.1\%) from Canada, 934 (33.7\%) from the USA and 336 (12.1\%) from Israel.

The study population and comparison between the population surveyed in phase 1 and phase 2 are presented in Table 1. Mean child age was $7.75 \pm 5.33$ years, $2003(72.4 \%)$ were under 12 years of age, and $1352(49 \%)$ were female. Eighty-nine percent $(n=2455)$ of parents reported their children were fully vaccinated according to the local pediatric schedule, and less than $2 \%(n=51)$ were against vaccinations in children. Almost $75 \%$ of the surveys were completed by mothers $(n=2064)$, and the mean age of respondents was 38.7 years (SD 8.0).

Three percent $(n=82)$ of respondents had a household member who was confirmed to have been infected with COVID-19 and $200(7.4 \%)$ children had a prior exposure to someone sick with COVID-19. Upon arrival to the ED, 732 (26.4\%) had symptoms that could have been caused by COVID-19 (e.g., fever, respiratory symptoms).

In phase 2, there were significantly more children exposed to COVID-19 at home, tested for the viral illness, and found at one point in time to be positive for COVID-19. Although there were significantly fewer children with COVID-19-related symptoms upon presentation in phase 2, caregivers were more concerned either they or their children were 
sick with COVID-19 at the time of presentation to the ED, compared to phase 1. All other demographic characteristics of children between phases were similar (Table 1).

Table 1. Characteristics of the survey population during the first phase (March-May 2020) and second phase (December 2020-March 2021). SD = Standard Deviation.

\begin{tabular}{|c|c|c|c|c|c|}
\hline & Surveys (2769) & $\begin{array}{c}\text { Total } \\
\text { Population }\end{array}$ & $\begin{array}{c}\text { Phase } 1 \\
(n=1728)\end{array}$ & $\begin{array}{l}\text { Phase } 2 \\
(n=1041)\end{array}$ & $p$-Value \\
\hline \multicolumn{6}{|l|}{ Child } \\
\hline Child's mean age in years (SD) & 2768 & $7.75(5.33)$ & $7.62(5.25)$ & $7.98(5.45)$ & 0.088 \\
\hline Child Under 12 Years of Age & 2768 & $2003(72.4 \%)$ & $1270(73.5 \%)$ & $733(70.4 \%)$ & 0.076 \\
\hline Child's gender female & 2762 & $1352(49.0 \%)$ & $861(50.0 \%)$ & $491(47.2 \%)$ & 0.006 \\
\hline Child has chronic illness & 2768 & $399(14.4 \%)$ & $238(13.8 \%)$ & $161(15.5 \%)$ & 0.243 \\
\hline Child uses chronic medication & 2768 & $493(17.8 \%)$ & $298(17.3 \%)$ & $195(18.7 \%)$ & 0.351 \\
\hline Child's immunizations up to date & 2748 & $2455(89.3 \%)$ & $1518(88.7 \%)$ & $937(90.4 \%)$ & 0.143 \\
\hline Child tested negative for COVID-19 & 2707 & $469(17.3 \%)$ & $136(8.06 \%)$ & $333(32.7 \%)$ & $<0.001$ \\
\hline $\begin{array}{l}\text { Someone at home was sick with } \\
\text { COVID-19 }\end{array}$ & 2715 & $82(3.02 \%)$ & $16(0.95 \%)$ & $66(6.43 \%)$ & $<0.001$ \\
\hline $\begin{array}{l}\text { Someone at home had exposure to } \\
\text { COVID-19 }\end{array}$ & 2711 & $200(7.38 \%)$ & $61(3.61 \%)$ & $139(13.6 \%)$ & $<0.001$ \\
\hline $\begin{array}{l}\text { Child had symptoms that may be } \\
\text { attributed to COVID-19 on arrival to } \\
\text { ED }\end{array}$ & 2769 & $732(26.4 \%)$ & $506(29.3 \%)$ & $226(21.7 \%)$ & $<0.001$ \\
\hline \multicolumn{6}{|l|}{ Caregiver } \\
\hline Completed by mother & 2769 & $2064(74.5 \%)$ & $1314(76.0 \%)$ & $750(72.0 \%)$ & 0.006 \\
\hline Caregiver's age & 2718 & $38.7(7.98)$ & $38.4(8.09)$ & $39.3(7.77)$ & 0.004 \\
\hline $\begin{array}{c}\text { Caregiver has higher than high school } \\
\text { education }\end{array}$ & 2709 & $2159(79.7 \%)$ & $1328(78.7 \%)$ & $831(81.3 \%)$ & 0.115 \\
\hline $\begin{array}{l}\text { Level of concern about child having } \\
\text { COVID-19 (Likert Scale 0-10) }\end{array}$ & 2667 & $1.99(3.12)$ & $1.78(2.96)$ & $2.36(3.34)$ & $<0.001$ \\
\hline $\begin{array}{c}\text { Level of concern about caregiver } \\
\text { having COVID-19 (Likert Scale 0-10) }\end{array}$ & 2649 & $1.78(2.90)$ & $1.60(2.74)$ & $2.10(3.12)$ & $<0.001$ \\
\hline $\begin{array}{l}\text { Level of concern about losing work } \\
\text { (Likert Scale } 0-10)\end{array}$ & 2623 & $2.93(3.63)$ & $2.76(3.61)$ & $3.21(3.66)$ & 0.003 \\
\hline $\begin{array}{l}\text { Level of concern about child losing } \\
\text { school (Likert Scale } 0-10)\end{array}$ & 2612 & $2.94(3.61)$ & $2.80(3.61)$ & $3.18(3.61)$ & 0.009 \\
\hline $\begin{array}{l}\text { Caregiver believes in social distancing } \\
\text { as a good public health measure }\end{array}$ & 2702 & $2493(92.3 \%)$ & $1583(92.3 \%)$ & $910(92.2 \%)$ & 0.981 \\
\hline $\begin{array}{l}\text { Caregiver had lost income due to } \\
\text { COVID-19 }\end{array}$ & 2694 & $1099(40.8 \%)$ & $718(41.9 \%)$ & $381(38.8 \%)$ & 0.120 \\
\hline
\end{tabular}

Overall, 1736 (62.7\%) caregivers planned to vaccinate their children against COVID19 , and among parents of children under 12 years of age, 1223/2003 (61.1\%) planned to vaccinate their children. Less caregivers planned to vaccinate their children against COVID19 in phase $2(1115 ; 64.5 \%)$, compared to phase $1(621 ; 59.7 \%)(p=0.002)$. For caregivers of children under 12 years, 808/1270 (63.6\%) said they will vaccinate their children in phase 1 , and $415 / 733(56.6 \%)$ in phase $2(p=0.002)$. Demographic characteristics and key parameters in the survey were similar among those parents willing to vaccinate young children in both phases (Table 2).

The most significant positive predictor of likelihood of a caregiver to report willingness to vaccinate their child against COVID-19 was their child being vaccinated per the recommended schedule. This finding was consistent across the entire cohort of caregivers, as well as for those with children under 12 years old. 
Table 2. Parents of children 12 years and younger who will vaccinate their children by phase of study.

\begin{tabular}{|c|c|c|c|c|}
\hline $\begin{array}{l}\text { Summary of Those Planning to Vaccine } \\
\text { Children under } 12 \text { Years }\end{array}$ & $\begin{array}{l}\text { Entire Cohort } \\
\qquad(n=2003)\end{array}$ & $\begin{array}{c}\text { Phase } 1 \\
\text { Will Vaccinate } \\
\quad(n=1270)\end{array}$ & $\begin{array}{c}\text { Phase } 2 \\
\text { Will Vaccinate } \\
\quad(n=733)\end{array}$ & $p$-Value \\
\hline Will vaccinate & $1223(61.1 \%)$ & $808(63.6 \%)$ & $415(56.6 \%)$ & 0.002 \\
\hline Child's age in Years (SD) * & $5.13(3.62)$ & $5.22(3.62)$ & $5.5(3.65)$ & 0.20 \\
\hline Child's immunization up-to-date & $1745(87.8 \%)$ & $731(91.0 \%)$ & $388(93.5 \%)$ & 0.17 \\
\hline Father completed the survey & $470(23.5 \%)$ & $206(25.5 \%)$ & $115(27.7 \%)$ & 0.59 \\
\hline Mother completed the survey & $1493(74.5 \%)$ & $588(72.8 \%)$ & $291(70.1 \%)$ & \\
\hline Other completed the survey & $40(2.00 \%)$ & $14(1.73 \%)$ & $9(2.17 \%)$ & \\
\hline Caregiver's age (Years) ${ }^{* *}$ & $36.7(7.14)$ & $37.2(7.41)$ & $38.2(6.63)$ & 0.02 \\
\hline $\begin{array}{l}\text { Parent has higher than high school } \\
\text { education }\end{array}$ & $1588(80.8 \%)$ & $651(82.2 \%)$ & $351(86.5 \%)$ & 0.07 \\
\hline $\begin{array}{l}\text { Level of concern about child having } \\
\text { COVID-19 (Likert scale 0-10) }\end{array}$ & $2.11(3.18)$ & $2.11(3.13)$ & $2.75(3.48)$ & 0.002 \\
\hline $\begin{array}{l}\text { Level of concern about losing work (Likert } \\
\text { scale } 0-10 \text { ) }\end{array}$ & $2.88(3.62)$ & $2.74(3.51)$ & $3.46(3.66)$ & 0.001 \\
\hline Parent had lost income due to COVID-19 & $806(41.6 \%)$ & $330(41.3 \%)$ & $144(36.9 \%)$ & 0.17 \\
\hline
\end{tabular}

When a multivariable analysis was conducted for the likelihood of caregivers vaccinating their children against COVID-19 once a vaccine is available for them (Table 3), in phase 1 , mothers were much less likely to vaccinate. Caregivers that were older, those worried the child had COVID-19 and those caregivers of children with up-to-date vaccinations were more likely to vaccinate for COVID-19. In phase 2, caregiver age and child's immunization status remained predictors of willingness to vaccinate against COVID-19. Concern about losing future work was also positive predictor, while previous lost income was a negative predictor (Table 3).

Table 3. Predictors of all caregivers' willingness to vaccinate their children against COVID-19 identified by multivariable logistic regression analysis in first phase (March-May 2020) and second phase (December 2020-March 2021).

\begin{tabular}{|c|c|c|c|c|c|c|}
\hline & \multicolumn{3}{|c|}{ Phase 1} & \multicolumn{3}{|c|}{ Phase 2} \\
\hline & Odds Ratio & $95 \% \mathrm{CI}$ & $p$-Value & Odds Ratio & $95 \%$ CI & $p$-Value \\
\hline Child's age in years (SD) * & 0.999 & $(0.997-1)$ & 0.326 & 1.00 & $(0.999-1)$ & 0.361 \\
\hline Child's immunization up-to-date & 2.54 & $(1.84-3.53)$ & $<0.001$ & 2.74 & $(1.70-4.51)$ & $<0.001$ \\
\hline \multicolumn{7}{|l|}{ Who completed the survey } \\
\hline \multicolumn{7}{|l|}{ Father (Reference) } \\
\hline Mother & 0.557 & $(0.415-0.742)$ & $<0.001$ & 1.01 & $(0.726-1.40)$ & 0.954 \\
\hline Other & 0.748 & $(0.385-1.51)$ & 0.403 & 1.31 & $(0.506-3.59)$ & 0.588 \\
\hline Caregiver's age (years) ${ }^{* *}$ & 1.03 & $(1.01-1.05)$ & $<0.001$ & 1.04 & $(1.02-1.07)$ & $<0.001$ \\
\hline $\begin{array}{l}\text { Parent has higher than high school } \\
\text { education }\end{array}$ & 1.24 & $(0.934-1.64)$ & 0.136 & 1.11 & $(0.748-1.64)$ & 0.606 \\
\hline $\begin{array}{l}\text { Level of concern about child having } \\
\text { COVID-19 (Likert scale 0-10) }\end{array}$ & 1.09 & $(1.04-1.13)$ & $<0.001$ & 1.01 & $(0.967-1.06)$ & 0.642 \\
\hline $\begin{array}{l}\text { Level of concern about losing work } \\
\text { (Likert Scale 0-10) }\end{array}$ & 1.00 & $(0.969-1.03)$ & 0.991 & 1.05 & (1.01-1.09) & 0.026 \\
\hline $\begin{array}{l}\text { Parent had lost income due to } \\
\text { COVID-19 }\end{array}$ & 0.852 & $(0.681-1.07)$ & 0.163 & 0.73 & $\begin{array}{l}(0.545- \\
0.977)\end{array}$ & 0.034 \\
\hline
\end{tabular}

${ }^{*}$ For one month increase. ${ }^{* *}$ For one year increase. 
When the multivariable analysis was conducted only including caregivers of children under 12 years of age (Table 4), we found in phase 1 that mothers and other caregivers were less likely to vaccinate, while older caregivers, those worried their children had COVID-19, and current up-to-date vaccinate status, were significantly associated with a plan to vaccinate their children. In phase 2 , caregiver age and child's immunization status remained predictors of willingness to vaccinate against COVID-19.

Table 4. Predictors of willingness to vaccinate against COVID-19 among caregivers of children under 12 years, identified by multivariable logistic regression analysis in first phase (March-May 2020) and second phase (December 2020-March 2021).

\begin{tabular}{|c|c|c|c|c|c|c|}
\hline & \multicolumn{3}{|c|}{ Phase 1} & \multicolumn{3}{|c|}{ Phase 2} \\
\hline & Odds Ratio & $95 \% \mathrm{CI}$ & $p$-Value & Odds Ratio & $95 \% \mathrm{CI}$ & $p$-Value \\
\hline Child's age in years $(\mathrm{SD}){ }^{*}$ & 0.999 & $(0.995-1)$ & 0.393 & 1 & $(0.997-1.01)$ & 0.392 \\
\hline Child's immunization up-to-date & 2.67 & $(1.87-3.83)$ & $<0.001$ & 1.97 & $(1.12-3.51)$ & 0.020 \\
\hline \multicolumn{7}{|l|}{ Who completed the survey } \\
\hline \multicolumn{7}{|l|}{ Father (Reference) } \\
\hline Mother & 0.522 & $(0.372-0.726)$ & $<0.001$ & 0.954 & $(0.647-1.4)$ & 0.810 \\
\hline Other & 0.335 & $(0.138-0.824)$ & 0.015 & 2.16 & $(0.555-10.9)$ & 0.298 \\
\hline Caregiver's age (years) ${ }^{* *}$ & 1.03 & $(1.01-1.05)$ & 0.006 & 1.04 & $(1.01-1.08)$ & 0.007 \\
\hline $\begin{array}{l}\text { Parent has higher than high school } \\
\text { education }\end{array}$ & 1.23 & $(0.877-1.72)$ & 0.230 & 1.43 & $(0.882-2.34)$ & 0.146 \\
\hline $\begin{array}{l}\text { Level of concern about child having } \\
\text { COVID-19 (Likert scale 0-10) }\end{array}$ & 1.1 & $(1.05-1.15)$ & $<0.001$ & 1.04 & (0.989-1.1) & 0.125 \\
\hline $\begin{array}{l}\text { Level of concern about losing work } \\
\text { (Likert Scale 0-10) }\end{array}$ & 0.996 & $(0.96-1.03)$ & 0.831 & 1.05 & (0.998-1.1) & 0.059 \\
\hline $\begin{array}{l}\text { Parent had lost income due to } \\
\text { COVID-19 }\end{array}$ & 0.917 & (0.708-1.19) & 0.510 & 0.725 & $(0.512-1.03)$ & 0.070 \\
\hline
\end{tabular}

${ }^{*}$ For one month increase. ${ }^{* *}$ For one year increase.

\section{Discussion}

Vaccinating children against COVID-19 is critical as a public health strategy, since they contribute to the spread of disease to higher risk adult populations [21] and in order to reduce the incidence of COVID-associated multisystem inflammatory system in children (MIS-C) [22].

When a modified survey was delivered in EDs seven months apart, demographics were very similar for those surveyed pre- and post-approval of a COVID-19 vaccine for adults. Fewer caregivers planned to vaccinate their children against COVID-19 in the postapproval phase. Caregivers of fully immunized children and older caregivers were most likely to immunize their children against COVID-19. In the larger group of caregivers, lost income due to the pandemic was a deterrent from vaccinating; however, those concerned about future lost wages were more likely to vaccinate. The latter two factors were not as important among caregivers of younger children.

Not surprisingly, we found more families were exposed to, or sick with, COVID19 during the second phase. Caregivers were also more worried about the child or the caregiver having COVID-19 when arriving at the ED.

In Bologna, Italy, during December 2020 and January 2021, an online survey reported that $60.4 \%$ of over 5000 parents were inclined to vaccinate, similar to findings in our cohort, and $29.6 \%$ were considering the opportunity [23]. Vaccine hesitancy $(9.9 \%)$ was higher among caregivers who were mothers of children aged 6-10 years, younger than 29 years old, had lower educational level, relied on information found on the web/social media, and disliked mandatory vaccination policies [23]. In a recent online survey in the U.S. with 427 participants, $44 \%$ planned to vaccinate children against COVID-19 once the 
vaccine becomes available to them [24], reflecting similar findings as in our cohort after the vaccine was approved in adults. However, $75 \%$ of children were reported to have chronic conditions, a much higher rate than in the general population, or the cohort of families completing our international study. Among parents of young infants and toddlers (18 month or younger) in the U.K., $48.2 \%$ reported "Definitely" and $40.9 \%$ "Unsure but leaning towards yes" for vaccinating their children [17], which reflects a much higher rate of likelihood to vaccinate than we found. In one online survey of factory workers in Shenzhen, China, from September 2020, a higher rate $(72.6 \%$ (764/1052)) of parents was willing to vaccinate their children for COVID-19. Family member's support and feeling the child will take up vaccination were associated with higher parental acceptability [25]. Among almost 5000 parents within the school public health network of the same region, hesitancy was $27.3 \%$ and parents with psychological distress were more likely to be hesitant about vaccinating their children [26]. A self-administered online survey in Turkey at the same time as our phase 2 revealed much lower willingness to vaccinate children (36.3\%) than in our survey, and in comparison to the rate of parents planning to get vaccinated themselves (59.9\%). Of interest, willingness increased to $83.9 \%$ if mortality associated with COVID-19 in children increased following a mutation [19]. In another survey from a Children's Hospital in Turkey, $66 \%$ of parents were reluctant to receive foreign COVID-19 vaccines, and $37 \%$ were reluctant to receive domestic COVID-19 vaccines [18]. These reports, along with our international sample, suggest significant geographic and timedependent variability in willingness to vaccinate children, and the multitude of factors that may affect parents in deciding on vaccinating against COVID-19.

Unfortunately, the ongoing pandemic is not associated with a shift towards vaccinating children; instead, parents are more hesitant, a source of great concern to the healthcare and scientific communities. The initial experience with safe adult COVID-19 vaccination in the countries participating in this study was not sufficiently reassuring for parents, and they did not report greater willingness to administer vaccines to their children, compared to pre-adult vaccine approval. This supports findings in a recent systematic review and metaanalysis on adults of 28 nationally representative samples $(n=58,656)$ from 13 countries during June-October 2020 [27], revealing a decline in willingness to vaccinate against COVID-19. It is possible that some parents felt reassured when hearing that children have a mild COVID-19 illness. Furthermore, at the time of this study, more information on COVID-19 presentation and course was available for parents through media and public health reports, compared to the initial period of the pandemic. Similar to our findings among parents, the meta-analysis reported females, younger, and of lower income or education level were consistently associated with limited willingness to get vaccinated [27].

Unlike our prior findings during the peak of the pandemic [16], desire to expedite vaccine research [28], and other reports on potential vaccine uptake [18,27], we found more balanced gender-dependent decision making on vaccination in the second phase of this study, and mothers were as likely as fathers to vaccinate (although confidence intervals overlapped between phases). This finding may be associated with the somewhat lower rate of mothers completing the second phase survey $(76 \%$ and $72 \%$ in the first and second phase, respectively), and that parents were slightly older. It is possible that early in the pandemic (phase 1), mothers, who are usually responsible for health care decision making at the household, took children more often to visit the ED. This may have changed as the pandemic continued (phase 2). We are uncertain why older parents brought their children in the second phase. Those findings are in contrast to a widening gap in attitudes between fathers and mothers found in the U.S. where a quarter of mothers said they are "extremely unlikely" to vaccinate their children [29]. If concerns about safety of the vaccine [24] affect caregiver decision making, potential association of one COVID19 vaccine to myocarditis in adolescents [30] may have further broadened this gap and public health organizations should find channels of communication directly to alleviate concerns expressed by caregivers. These may include advertising on social media channels 
to subgroups of the population, or through particular school systems in regions with a known high rate of vaccine hesitancy.

Of interest, those already affected by pandemic-related lost income prior to entering the study did not seem to be interested in vaccinating their children, while those reporting more fear of future lost work favored vaccination. Perhaps parents who are worried about imminent or potential lost work, which frequently they have little control over, would like their children to get vaccinated as an activity they can control and, this way, to reduce the need to decide on vaccination at a later date while adding burden on the family. Among parents of young children $(<12$ years), economic factors were not significantly different between the two phases. More research is needed to explore these attitudes and age-related differences, likely by means of qualitative methodology, in order to understand parental priorities around health-related and economic-related factors. Vaccine hesitancy is an important factor in the decision to vaccinate children during this pandemic, and our study suggest that over $40 \%$ of caregivers need to be convinced to vaccinate their young children; addressing this will be an important part of a worldwide effort to reach herd immunity and achieve a post-pandemic world. Overcoming COVID-19 vaccine hesitancy among adults for their own vaccination may not be transferred to their interest in vaccination of their children, as we have shown at the peak of the pandemic [31]. Uncovering specific reasons for COVID-19 vaccine hesitancy is an urgent task and will help regional public health agencies ensure parents receive the answers to questions they have when considering available vaccines. Furthermore, the relationship between parents and health care providers affects their vaccine decision making [11], and communication strategies by providers are essential during the COVID-19 ongoing pandemic. Approaching families with older parents who are already convinced that a child needs to be fully vaccinated may result in earlier gains in vaccinating children, especially those under 12 years.

Our study has several limitations. First, as with many surveys, it is unlikely to be a representative sample of families visiting the EDs or the entire population in these three countries and, therefore, we cannot rule out response or selection biases. We also did not collect information on how many parents were already vaccinated at the time they responded to the survey in phase 2 (vaccines for adults were available under emergency authorization). Furthermore, as data on adverse events of vaccines continue to be published in the media, parents may have different perspectives than during the time our survey took place. Finally, rate of vaccination in different regions participating in the study may have affected parental attitudes.

\section{Conclusions}

In summary, $44 \%$ of caregivers do not plan to vaccinate their children against COVID19 , a higher rate than was seen in a similar cohort before vaccines for adults were approved. Older caregivers who fully vaccinated their children are more likely to vaccinate their 12-18 years old children now that the vaccine has been authorized for emergency use for this age group, and for younger children (under 12 years old) once it is available. These data could help in designing target strategies to implement adherence to a vaccination campaign. Health care providers can harness these findings to identify vaccine hesitancy among parents in their practice and communicate the importance of vaccinating young children, even before vaccines are available for this age group.

Author Contributions: Conceptualization and methodology, R.D.G., E.J.K. and J.C.B.; formal analysis, J.N.B.; investigation, and data curation, all authors; writing —original draft preparation, R.D.G.; writing - review and editing, all authors. All authors have read and agreed to the published version of the manuscript.

Funding: This research received no external funding.

Institutional Review Board Statement: This study was approved by each site's local Institutional Review Board (IRB). See methods for more detail.

Informed Consent Statement: Not applicable. 
Data Availability Statement: Data will be made available upon request.

Acknowledgments: International COVID-19 Parental Attitude Study (COVIPAS) Group Information (alphabetic): Sarah Ahmed, MD, Ta Department of Emergency Medicine, Mary Bridge Children's Hospital, Tacoma, WA, USA; Samina Ali, MDCM, FRCPC, Department of Pediatrics, Faculty of Medicine \& Dentistry, Women and Children's Health Research Institute, University of Alberta, Edmonton, AB, Canada; Julie C. Brown, Seattle Children's Hospital and University of Washington School of Medicine, Seattle, WA, USA; Adrienne L. Davis, MSc, Pediatric Emergency Medicine, Hospital for Sick Children and University of Toronto, ON, Canada; Nathalie Gaucher, Division of Emergency Medicine, Department of Pediatrics, CHU Sainte-Justine, Université de Montréal, Montréal, Québec, Canada; Gualco Gianluca, Pediatric Emergency Department, Pediatric Institute of Italian part of Switzerland, Ticino, Switzerland; Ran Goldman, The Pediatric Research in Emergency Therapeutics (PRETx) Program, Division of Emergency Medicine, Department of Pediatrics, University of British Columbia, and BC Children's Hospital Research Institute, Vancouver, BC, Canada; Mark Griffiths, Division of Pediatric Emergency Medicine, Children's Healthcare of Atlanta, Emory School of Medicine, Atlanta, GA, USA; Jeanine E. Hall, Division of Emergency and Transport Medicine, Children's Hospital Los Angeles, USC Keck School of Medicine, Los Angeles, CA, USA; Matt Hansen, Department of Emergency Medicine, Oregon Health and Sciences University, Portland, USA; Thomas L. Hurt, Department of Emergency Medicine, Mary Bridge Children's Hospital, Tacoma, WA, USA; Christopher Kelly, Department of Pediatric Emergency Medicine, New York Presbyterian Brooklyn Methodist Hospital, New York, USA; Eileen J. Klein, Seattle Children's Hospital and University of Washington School of Medicine, Seattle, WA, USA; Adi Klein, Department of Pediatrics, Hillel Yaffe Medical Center, Hadera and Technion Faculty of Medicine, Haifa, Israel.; Eran Kozer, Sackler Faculty of Medicine, Tel Aviv University, Be'er Yakov, Israel; Danna Krupik, Pediatric Emergency Unit, Ziv Medical Center, Israel. Azrieli Faculty of Medicine, Bar-Ilan University, Safed, Israel; Shashidhar Marneni, Department of Pediatric Emergency Medicine, Children's Medical Center of Dallas, UT Southwestern Medical Center, Dallas, TX, USA; Ahmed Mater, Pediatric Emergency Medicine, Jim Pattison Children's Hospital, and University of Saskatchewan, Saskatoon, SK, Canada; Rakesh Mistry, Department of Emergency Medicine, Children's Hospital Colorado Anschutz Medical Campus, Aurora, USA; Cristina Parra, Hospital Sant Joan de Déu Barcelona, Pediatric Emergency Department, Barcelona, Spain; Naveen Poonai, Departments of Paediatrics, Internal Medicine, Epidemiology \& Biostatistics, Schulich School of Medicine \& Dentistry, Western University, and Children's Health Research Institute, London, Ontario, Canada; David Sheridan, Department of Emergency Medicine, Oregon Health and Sciences University, Portland, USA; Naoki Shimizu, Department of Pediatrics, St. Marianna University School of Medicine, Tokyo, Japan; Kenneth Yen, Department of Pediatrics, Division of Pediatric Emergency Medicine, University of Texas Southwestern Children's Health, Dallas, Texas, USA; Esther L. Yue, Department of Emergency Medicine, Oregon Health and Sciences University, Portland, USA.

Conflicts of Interest: The authors declare no conflict of interest.

\section{References}

1. Mahase, E. Covid-19: What do we know so far about a vaccine? BMJ 2020, 369, m1679. [CrossRef] [PubMed]

2. MacDonald, N.E.; SAGE Working Group on Vaccine Hesitancy. Vaccine hesitancy: Definition, scope and determinants. Vaccine 2015, 33, 4161-4164. [CrossRef] [PubMed]

3. Pires, C. What Is the State-of-the-Art in Clinical Trials on Vaccine Hesitancy 2015-2020? Vaccines 2021, 9, 348. [CrossRef] [PubMed]

4. Imahorn, N.; Heininger, U. What Matters to Parents Regarding Immunization of Their Children: Systematic Analysis of Expert Advice to Parents in an Internet Forum. Pediatr. Infect. Dis. J. 2020, 39, 157-163. [CrossRef] [PubMed]

5. Williams, S.E. What are the factors that contribute to parental vaccine-hesitancy and what can we do about it? Hum. Vaccin. Immunother. 2014, 10, 2584-2596. [CrossRef]

6. Esposito, S.; Principi, N.; Cornaglia, G.; ESCMID Vaccine Study Group (EVASG). Barriers to the vaccination of children and adolescents and possible solutions. Clin. Microbiol. Infect. 2014, 20 (Suppl. 5), 25-31. [CrossRef]

7. WHO. Ten Threats to Global Health in 2019. Available online: https:/ /www.who.int/emergencies/ten-threats-to-global-healthin-2019 (accessed on 18 September 2021).

8. Kempe, A.; Saville, A.W.; Albertin, C.; Zimet, G.; Breck, A.; Helmkamp, L.; Vangala, S.; Dickinson, L.M.; Rand, C.; Humiston, S.; et al. Parental Hesitancy About Routine Childhood and Influenza Vaccinations: A National Survey. Pediatrics 2020, 146, e20193852. [CrossRef] 
9. Szilagyi, P.G.; Shah, M.D.; Delgado, J.R.; Thomas, K.; Vizueta, N.; Cui, Y.; Vangala, S.; Shetgiri, R.; Kapteyn, A. Parents' Intentions and Perceptions About COVID-19 Vaccination for Their Children: Results from a National Survey. Pediatrics 2021, 3, e2021052335. [CrossRef]

10. Hargreaves, A.L.; Nowak, G.; Frew, P.; Hinman, A.R.; Orenstein, W.A.; Mendel, J.; Aikin, A.; Nadeau, J.A.; McNutt, L.A.; Chaimberlain, A.T.; et al. Adherence to Timely Vaccinations in the United States. Pediatrics 2020, 145, e20190783. [CrossRef]

11. McGregor, S.; Goldman, R.D. Determinants of parental vaccine hesitancy. Can. Fam. Phys. 2021, 67, 339-341. [CrossRef]

12. Schmid, P.; Rauber, D.; Betsch, C.; Lidolt, G.; Denker, M.L. Barriers of Influenza Vaccination Intention and Behavior-A Systematic Review of Influenza Vaccine Hesitancy, 2005-2016. PLoS ONE 2017, 12, e0170550. [CrossRef]

13. Olson, O.; Berry, C.; Kumar, N. Addressing Parental Vaccine Hesitancy towards Childhood Vaccines in the United States: A Systematic Literature Review of Communication Interventions and Strategies. Vaccines 2020, 8, 590. [CrossRef]

14. Pew Research Center. Intent to Get a COVID-19 Vaccine Rises to 60\% as Confidence in Research and Development Process Increases. Available online: https:/ / www.pewresearch.org/science/2020/12/03/intent-to-get-a-covid-19-vaccine-rises-to-60 -as-confidence-in-research-and-development-process-increases / (accessed on 18 September 2021).

15. Invisibly. Parents Are Cautious to Vaccinate Their Kids Against COVID. Available online: https://www.invisibly.com/insights/ kids-covid-vaccination (accessed on 18 September 2021).

16. Goldman, R.D.; Yan, T.D.; Seiler, M.; Parra Cotanda, C.; Brown, J.C.; Klein, E.J.; Hoeffe, J.; Gelernter, R.; Hall, J.E.; Davis, A.L.; et al. Caregiver willingness to vaccinate their children against COVID-19: Cross sectional survey. Vaccine 2020, 38, 7668-7673. [CrossRef]

17. Bell, S.; Clarke, R.; Mounier-Jack, S.; Walker, J.L.; Paterson, P. Parents' and guardians' views on the acceptability of a future COVID-19 vaccine: A multi-methods study in England. Vaccine 2020, 38, 7789-7798. [CrossRef]

18. Yigit, M.; Ozkaya-Parlakay, A.; Senel, E. Evaluation of COVID-19 Vaccine Refusal in Parents. Pediatr. Infect. Dis. J. 2021, 40, e134-e136. [CrossRef]

19. Y1lmaz, M.; Sahin, M.K. Parents' willingness and attitudes concerning the COVID-19 vaccine: A cross-sectional study. Int. J. Clin. Pract. 2021, 75, e14364. [CrossRef]

20. CTV News. Children 12 and Older Now Cleared to Receive Pfizer Vaccine: Health Canada. Available online: https://www. ctvnews.ca/health/coronavirus/children-12-and-older-now-cleared-to-receive-pfizer-vaccine-health-canada-1.5414935 (accessed on 18 September 2021).

21. Shah, S. Children and the American Rescue Plan: Countering COVID-19 vaccine hesitancy during a global pandemic. Pediatr. Res. 2021, 25, 1-3. [CrossRef]

22. Chiotos, L.; Hayes, M.; Kimberlin, D.W.; Jones, S.B.; James, S.H.; Pinninti, S.G.; Yarbrough, A.; Abzug, M.J.; MacBrayne, C.E.; Soma, V.L.; et al. Multicenter Interim Guidance on Use of Antivirals for Children with Coronavirus Disease 2019/Severe Acute Respiratory Syndrome Coronavirus 2. J. Pediatr. Infect. Dis. Soc. 2021, 10, 34-48. [CrossRef] [PubMed]

23. Montalti, M.; Rallo, F.; Guaraldi, F.; Bartoli, L.; Po, G.; Stillo, M.; Perrone, P.; Squillace, L.; Dallolio, L.; Pandolfi, P. Would Parents Get Their Children Vaccinated Against SARS-CoV-2? Rate and Predictors of Vaccine Hesitancy According to a Survey over 5000 Families from Bologna, Italy. Vaccines 2021, 9, 366. [CrossRef] [PubMed]

24. Ruggiero, K.M.; Wong, J.; Sweeney, C.F.; Avola, A.; Auger, A.; Macaluso, M.; Reidy, P. Parents' Intentions to Vaccinate Their Children Against COVID-19. J. Pediatr. Health Care 2021, 35, 509-517. [CrossRef]

25. Zhang, K.C.; Fang, Y.; Cao, H.; Chen, H.; Hu, T.; Chen, Y.Q.; Zhou, X.; Wang, Z. Parental Acceptability of COVID-19 Vaccination for Children Under the Age of 18 Years: Cross-Sectional Online Survey. JMIR Pediatr. Parent 2020, 3, e24827. [CrossRef]

26. Xu, Y.; Zhang, R.; Zhou, Z.; Fan, J.; Liang, J.; Cai, L.; Peng, L.; Ren, F.; Lin, W. Parental psychological distress and attitudes towards COVID-19 vaccination: A cross-sectional survey in Shenzhen, China. J. Affect. Disord. 2021, 292, 552-558. [CrossRef]

27. Robinson, E.; Jones, A.; Lesser, I.; Daly, M. International estimates of intended uptake and refusal of COVID-19 vaccines: A rapid systematic review and meta-analysis of large nationally representative samples. Vaccine 2021, 39, 2024-2034. [CrossRef] [PubMed]

28. Goldman, R.D.; Marneni, S.R.; Seiler, M.; Brown, J.C.; Klein, E.J.; Cotanda, C.P.; Gelernter, R.; Yan, T.D.; Hoeffe, J.; Davis, A.L.; et al. Caregivers' Willingness to Accept Expedited Vaccine Research During the COVID-19 Pandemic: A Cross-sectional Survey. Clin. Ther. 2020, 42, 2124-2133. [CrossRef] [PubMed]

29. Simonson, M.D.; Chwe, H.; Lazer, D.; Ognyanova, K.; Baum, M.; Perlis, R.H.; Lin, J. The COVID States Project \#49: Vaccinating America's Youth. 2021. Available online: https:/ / osf.io/stacj/ (accessed on 18 September 2021).

30. Wise, J. Covid-19: Should we be worried about reports of myocarditis and pericarditis after mRNA vaccines? BMJ 2021, 373, n1635. [CrossRef] [PubMed]

31. Goldman, R.D.; Staubli, G.; Cotanda, C.P.; Brown, J.C.; Hoeffe, J.; Seiler, M.; Gelernter, R.; Hall, J.E.; Griffiths, M.A.; Davis, A.L.; et al. Factors associated with parents' willingness to enroll their children in trials for COVID-19 vaccination. Hum. Vaccin. Immunother. 2021, 17, 1607-1611. [CrossRef] 